\title{
Simultaneous quantitation and monitoring of rosuvastatin with NSAIDs by liquid chromatography with UV detection
}

This article was published in the following Dove Press journal:

Research and Reports in Medicinal Chemistry

12 October 2012

Number of times this article has been viewed

\author{
Muhammad Saeed Arayne' \\ Najma Sultana ${ }^{2}$ \\ Arman Tabassum ${ }^{\prime}$ \\ 'Department of Chemistry; \\ ${ }^{2}$ Department of Pharmaceutical \\ Chemistry, Faculty of Pharmacy, \\ University of Karachi, Karachi, Pakistan
}

Correspondence: Arman Tabassum Department of Chemistry, University of Karachi, Karachi 75270, Pakistan Fax +923332101 255 Email arman_tabassum@hotmail.com
Overview and methods: A simple, accurate, and sensitive high-performance liquid chromatography-ultraviolet detection method was developed for simultaneous determination of rosuvastatin with co-administered nonsteroidal anti-inflammatory drugs (meloxicam, ibuprofen, and mefenamic acid) in active pharmaceutical ingredient (API), pharmaceutical formulations, and human serum. Isocratic separation was employed on prepacked Purospher Star $\mathrm{C}_{18}(5 \mu \mathrm{m}, 25 \times 0.46 \mathrm{~cm})$ columns at ambient temperature. The mobile phase consisted of methanol:water:acetonitrile $(80: 17.5: 2.5 \mathrm{v} / \mathrm{v})$, $\mathrm{pH}$ adjusted to 3.0 with $o$-phosphoric acid at $1 \mathrm{~mL} \mathrm{~min}{ }^{-1}$. The drugs in the eluant were monitored at isosbestic point of drugs at $230 \mathrm{~nm}$. The method was compared by programming the detector adjusting the wavelength with time to match the individual analyte's chromophore which enhanced sensitivity with linear range.

Results: Linear behavior was observed between 0.1 and $2.5 \mu \mathrm{gmL}^{-1}$ for rosuvastatin, 0.4 and $10 \mu \mathrm{gmL}^{-1}$ for meloxicam, 0.25 and $6.25 \mu \mathrm{gmL}^{-1}$ for ibuprofen, and 0.15 and $3.75 \mu \mathrm{gmL}^{-1}$ for mefenamic acid, with $\mathrm{r}^{2}>0.998$. The relative standard deviation for inter-day precision was $<2$ in API, formulations, and human serum. Percent recovery for all drugs was $97.3 \%-100.89 \%$ in API and formulations and $99.3 \%-100.4 \%$ in human serum. Wavelength-programmed analysis made the method more sensitive, where $4<$ limit of quantification (LOQ) $<11$ and $1<$ limit of detection (LOD) $<4 \mathrm{ngmL}^{-1}$ for API; $6<\mathrm{LOQ}<10$ and $2<\mathrm{LOD}<3 \mathrm{ngmL}^{-1}$ for pharmaceutical formulations; and $3<\mathrm{LOQ}<10$ and $1<\mathrm{LOD}<3 \mathrm{ngmL}^{-1}$ in human serum, reduced from $9<$ LOQs $<23$ and $3<$ LODs $<7 \mathrm{ngmL}^{-1}$ for all drug analytes in API; and $4<$ LOQs $<17$ and $1<$ LODs $<6 \mathrm{ngmL}^{-1}$ in human serum recorded at isosbestic point for rosuvastatin, meloxicam, ibuprofen, and mefenamic acid, respectively. Recovery of drugs was $99.998 \%-104.000 \%$ in all API, formulations, and serum samples.

Conclusion: The proposed method can be used for the quantitative analysis of these drugs in raw materials, in bulk drugs, dosage formulations and in human serum and for clinical studies even when the drug is present in low amounts.

Keywords: meloxicam, ibuprofen, mefenamic acid, liquid chromatography, quantitative analysis

\section{Introduction}

Rosuvastatin (ROS) is an oral drug for lowering blood cholesterol levels and belongs to the HMG-CoA reductase inhibitors, chemically a 6-heptenoic acid - (3R,5S,6E)-7[4-(4-fluorophenyl)-2-(N-methylmethanesulfonamido)-6-(propan-2-yl)pyrimidin5-yl]-3,5-dihydroxyhept-6-enoic acid - calcium salt (Figure 1). ${ }^{1-3}$ Subjects with hyperlipidemia and hypercholesterolemia aged older than 40 years usually suffer from anti-inflammatory disorders as well for which they are prescribed nonsteroidal anti-inflammatory drugs (NSAIDs). 
<smiles>CC(C)c1nc(N(C)S(C)(=O)=O)nc(-c2ccc(F)cc2)c1/C=C/[C@H](O)C[C@@H](O)CC(=O)O</smiles>

C

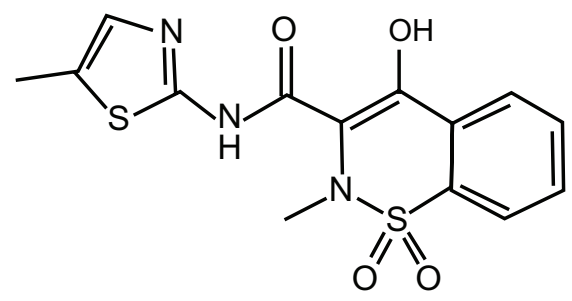

B<smiles>Cc1cnc(NC(=O)C2=C(O)c3ccccc3S(=O)(=O)N2C)s1</smiles>

D

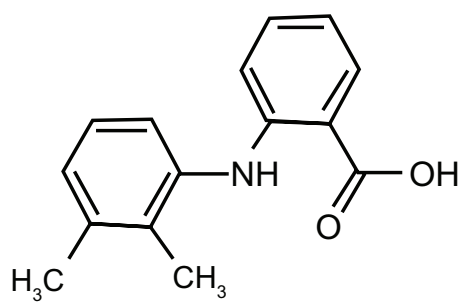

Figure I Chemical structures of $(\mathbf{A})$ rosuvastatin, (B) meloxicam, (C) ibuprofen, and (D) mefenamic acid.

Determination of ROS has been reported alone; ${ }^{4-6}$ with other statins such as simvastatin and pravastatin sodium; ${ }^{7}$ and in pharmacological, pharmacokinetic, and analytical studies in combination with atorvastatin, lovastatin, pravastatin, and simvastatin. ${ }^{8}$ ROS has also been determined with atenolol, spironolactone, glibenclamide, and naproxen sodium; ${ }^{9}$ pioglitazone, gliquidone, and simvastatin; ${ }^{10}$ simvastatin, atorvastatin, pravastatin, and ceftriaxone $;{ }^{11}$ diltiazem, atorvastatin, and simvastatin; ${ }^{12}$ lisinopril, pravastatin, and atorvastatin $;{ }^{13}$ captopril, atorvastatin, and simvastatin; ${ }^{14}$ and lisinopril, captopril, and enalapril. ${ }^{15}$

Methods have also been developed for NSAIDs, ${ }^{16-19}$ including ibuprofen (IBU). ${ }^{20-27}$ In 2000, Velpandian et al ${ }^{28}$ reported a high-performance liquid chromatography (HPLC) method for the determination of meloxicam (MEL) in biological samples. Methods for the determination of MEL in plasma using liquid chromatography (LC) have been developed by Dasandi et $\mathrm{al}^{29}$ and Baeyens et al. ${ }^{30}$ Liquid chromatographic method has also been reported for determining MEL in bulk drug and pharmaceutical formulation by Zawilla et al ${ }^{31}$ and Arayne et al. ${ }^{32}$

Mefenamic acid (MEF) has been determined simultaneously with drotaverine $\mathrm{HCl},{ }^{33,34}$ with ethamsylate, ${ }^{35}$ and with tranexamic acid. ${ }^{36}$ Our research group has been working for some time on the simultaneous determination of co-administered drugs ${ }^{9-15}$ as NSAIDs with lisinopril, ${ }^{37}$ sparfloxacin, ${ }^{38}$ and metformin. ${ }^{39-41}$ Sun and colleagues have worked on the simultaneous determination of NSAIDs at their absorption maxima. ${ }^{42}$

The present work describes a simple reverse phase (RP)-HPLC method for the simultaneous determination of ROS with IBU, MEL, and MEF in active pharmaceutical ingredient (API), dosage formulations, and human serum. A method such as this is needed for co-administration of drugs in multiple-drug therapy and, as far as the authors are aware, there is no such method reported in the literature for simultaneous determination of ROS and NSAIDs. Our present work is also unique because it includes the analysis of drugs by programming the detector adjusting the wavelength with time to match the individual analyte's chromophore which enhanced the sensitivity with linearity range. The use of a conventional ultraviolet (UV) detector in the system, without the installation of drug-sensitive or expensive detectors with isocratic elution, increased the sensitivity of the method, raising it to the level of the nanogram. The method is applicable for drug-drug interaction studies between ROS and NSAIDs as well as pharmaceutical and clinical routine analyses.

\section{Experimental}

\section{Materials and reagents}

ROS, MEL, IBU, and MEF active ingredients were kind gifts from PharmEvo (Karachi, Pakistan), Hilton Pharma Karachi (Karachi, Pakistan), Abbot Laboratories (Karachi, Pakistan), 
and Pfizer Pakistan (Ltd.) (Karachi, Pakistan), respectively, while their dosage formulations, ROS (X-plended $5 \mathrm{mg}$ tablets, PharmEvo), MEL (Xobix 7.5 mg tablets, Hilton Pharma Karachi), IBU (Brufen $200 \mathrm{mg}$ tablets Abbot Laboratories (Karachi, Pakistan)), and MEF (Ponstan ${ }^{\circledR} 250 \mathrm{mg}$ tablets) Pfizer Laboratories, Karachi, Pakistan were purchased from a local market. $O$-phosphoric acid, methanol, and acetonitrile (ACN) of HPLC grade were purchased from Merck (Darmstadt, Germany). Double-distilled de-ionized water was used throughout the experiments and was prepared freshly daily.

\section{Apparatus}

Two HPLC systems were used in this research: a Shimadzu 10A HPLC System and a Shimadzu 20A HPLC System (Kyoto, Japan), both with LC-20-AT HPLC pumps; SPD-20A Shimadzu UV visible detectors; CBM-102 communication Bus Modules (Shimadzu) - to record the chromatographic and integrated data; and Shimadzu Class-GC 10 software (v 5.03). Chromatographic separations were carried out on Purospher ${ }^{\circledR}$ STAR $_{18}(5 \mu \mathrm{m}, 250 \times 0.46 \mathrm{~cm})($ Merck Millipore $)$ and Sapilco ${ }^{\circledR} \mathrm{C}_{18}(5 \mu \mathrm{m}, 250 \times 0.46 \mathrm{~cm})$ columns (Sigma-Aldrich, St Louis, MO) for ruggedness studies of the method. A Shimadzu UV-1800 spectrophotometer was used for the detection of the maximum drug absorption. Deionization of water was carried out using a Stedec CSW300 deionizer (Stedec (Pvt) Ltd., Karachi, Pakistan) and sonication and degassing of mobile phase was carried out with an Elma Ultrasonic LC $30 \mathrm{H}$ sonicator (Elmer, NY).

\section{Preparation of standard solutions}

Standard stock solutions of ROS, MEL, IBU, and MEF were prepared by dissolving their appropriate amounts in diluents of mobile phase and afterwards adjusted to the mark for $100 \mathrm{~mL} / \mathrm{min}$. These stock solutions were subsequently used in the preparation of working standards by further dilution. All stock solutions were kept in refrigerator at $4{ }^{\circ} \mathrm{C}$. Working solutions were made from 0.025 to $2.500 \mu \mathrm{gmL}^{-1}$ for ROS, 0.1 to $10.0 \mu \mathrm{gmL}^{-1}$ for MEL, 0.0625 to $6.2500 \mu \mathrm{gmL}^{-1}$ for IBU, and 0.0375 to $3.7500 \mu \mathrm{gmL}^{-1}$ for $\mathrm{MEF}$.

\section{Chromatographic conditions}

After a number of trials by varying the parameters of solvent compositions, $\mathrm{pH}$, flow rates, shortest retention times, and best resolution among the peaks of the analytes, the optimum conditions were achieved. The mobile phase, methanol:water:ACN (80:17.5:2.5 v/v/v) was filtered through a membrane filter ( 0.45 micron) and degassed in ultrasonic bath for 10 minutes. The analytes were isocratically eluted with the mobile phase at a flow rate of $1.0 \mathrm{~mL} / \mathrm{min}$. The mobile phase was brought to $\mathrm{pH} 3.0$ by $o$-phosphoric acid against a Purospher STAR $\mathrm{C}_{18}(5 \mu \mathrm{m}, 250 \times 0.46 \mathrm{~cm})$ column as the stationary phase. The retention times of ROS, MEL, IBU, and MEF were 3.6, 5.0, 7.8, and 11.9 minutes, respectively. Samples of $20 \mu \mathrm{L}$ were injected for a single run through a rheodyne sample loop. The method was first developed and validated at $230 \mathrm{~nm}$, the isosbestic point of drugs, then at their individual $\lambda_{\text {max }}: 240 \mathrm{~nm}, 361 \mathrm{~nm}, 230 \mathrm{~nm}$, and $282 \mathrm{~nm}$ for ROS, MEL, IBU, and MEF, respectively (these were found by scanning them on a UV spectrophotometer (Figure 2) by programming the UV detector for 0-4.2, 4.3-5.8, 5.9-8.8 and 8.9-13.2 minutes for ROS, MEL, IBU, and MEF, respectively, at a flow rate of $1 \mathrm{~mL} / \mathrm{min}^{-1}$ ).

\section{Preparation of solutions of ROS and NSAIDs in pharmaceutical formulations}

The contents of ten tablets each of ROS, MEL, IBU, and MEF were finely ground separately. An accurately weighed powdered sample containing the labeled amount of each drug was transferred to a $100 \mathrm{~mL}$ volumetric flask. The volume was adjusted with mobile phase and the resultant solution was sonicated for 5 minutes. A portion of the solution was then filtered through a $0.45 \mu \mathrm{m}$ Millipore filter paper (Billerica, MA) and appropriately diluted. An aliquot $(20 \mu \mathrm{L})$ of each solution was injected into the column.

\section{Preparation of solutions of ROS and NSAIDs in human serum}

A $3 \mathrm{~mL}$ sample of blood from a healthy volunteer (aged 24 years) was collected in an evacuated glass tube through an indwelling cannula placed in the forearm vein at Fatimid Foundation (Karachi, Pakistan). The volunteer was not taking any medication, a smoker, or undertaking any strenuous activity. The blood was shaken and centrifuged at 10,000 rpm for 10 minutes to separate out the plasma. A total of $9 \mathrm{~mL} \mathrm{ACN}$ was added to $1 \mathrm{~mL}$ plasma and centrifuged at $10,000 \mathrm{rpm}$ for 10 minutes to deproteinate it. ${ }^{14,43}$ The supernatant serum thus obtained from the plasma was filtered and used for analysis and stored at $-20^{\circ} \mathrm{C}$. Working solutions of various concentrations - that is, $0.025-2.5 \mu \mathrm{gmL}^{-1}$ for ROS, $0.1-10 \mu \mathrm{gmL}^{-1}$ for MEL, 0.0625-6.25 $\mu \mathrm{gmL}^{-1}$ for IBU, and 0.0375-3.75 $\mu \mathrm{gmL}^{-1}$ for MEF - were prepared by spiking the serum with stock solutions maintaining the ratio of 1:1 (drug stock diluted by diluent:serum v/v). Triplicate injections were made for each working solution for the analysis in serum. 


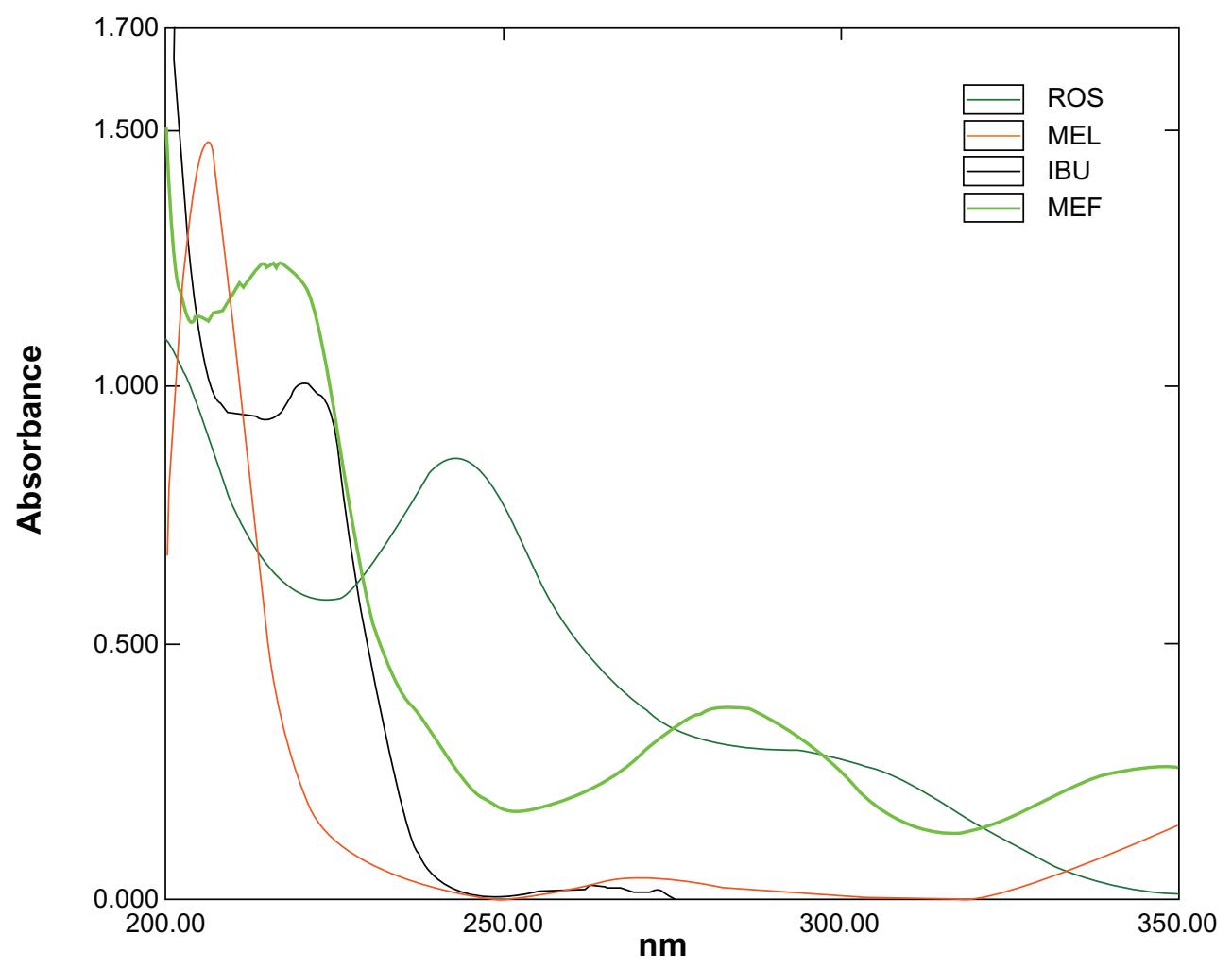

Figure 2 Representative ultraviolet spectra of rosuvastatin (ROS), ibuprofen (IBU), and mefenamic acid (MEF).

\section{Results and discussion}

The development of HPLC methods for the determination of drugs has received considerable attention in recent years because of their importance in the quality control of drugs and drug products. The newly developed method for determination of ROS and NSAIDs (MEL, IBU, and MEF) described here has been validated and holds well for determination of drugs in raw materials, dosage formulations, and human serum, as the literature survey revealed that no UV or LC methods have been reported for the simultaneous determination of ROS in combination with MEL, IBU, and MEF in bulk and pharmaceutical formulations. The present paper describes our attempt to develop a rapid, more accurate, precise, 1, economical, and less time-consuming method based on RP-HPLC separation simultaneously combined with UV detection for ROS and NSAIDs as raw materials, in bulk drug samples, dosage formulations, and, especially, human serum.

\section{Method optimization}

In this study, an isocratic separation of ROS from MEL, IBU and MEF in standard solution of active pharmaceuticals, formulations and human serum was carried out using methanol:water: $\mathrm{ACN}(80: 17.5: 2.5, \mathrm{v} / \mathrm{v} / \mathrm{v})$ as the mobile phase adjusted to $\mathrm{pH} 3.0$ with $o$-phosphoric acid.

Since quality control analyses, in vitro and in vivo interactions, and pharmacokinetic studies require very specific methods for the analytes, optimized conditions need to be adopted after studying various parameters selective to the drug analytes. Each drug analyte was scanned on a UVvisible spectrophotometer to detect similar absorptivity at its maxima, called its "isosbestic point," $(230 \mathrm{~nm})$ at the $\lambda_{\text {max }}(240 \mathrm{~nm}, 361 \mathrm{~nm}, 230 \mathrm{~nm}$, and $282 \mathrm{~nm}$, for ROS, MEL, IBU, and MEF, respectively) of ROS, MEL, IBU, and MEF (spectra shown in Figure 2).

Different ratios of methanol and water were taken as the starting test solvents for the mobile phase considering peak parameters, ease of separation, and cost: 95:5, $90: 10,85: 15,80: 20$, and $75: 25 \mathrm{v} / \mathrm{v}$ of methanol:water were tested. The ratio $80: 20 \mathrm{v} / \mathrm{v}$ of methanol:water gave better peak separation and resolution, while the lower ratios gave larger retention times and broader peaks; above this ratio, the retention times were closer and merged. Further, the addition of ACN with the ratio 80:17.5:2.5 methanol:water:ACN v/v/v gave sharper and better resolved peaks. 
Investigating for $\mathrm{pH}$ effect from 2.5 to 4.5 , the peaks were well resolved and sharp when the $\mathrm{pH}$ was adjusted to 3.0. The peak area of each compound remarkably decreased when the $\mathrm{pH}$ value of the mobile phase was above 3.5 , whereas there were little changes up to $\mathrm{pH} 3.2$. Thus, $\mathrm{pH} 3.0$ was chosen as optimal. $O$-phosphoric acid was used for $\mathrm{pH}$ adjustment due to its inertness towards the column packing.

The Purospher Star $\mathrm{C}_{18}(5 \mu \mathrm{m}, 250 \times 0.46 \mathrm{~cm})$ column was found efficient for the reproducible separation of nonpolar compounds, minimizing solvent usage with typical peak symmetry. The ROS, MEL, IBU, and MEF eluted at 3.6, 5.0, 7.8 , and 11.9 minutes, respectively, from the column at $1 \mathrm{~mL} /$ $\mathrm{min}^{-1}$ at isocratic condition. After the method was developed and optimized, it was validated.

\section{Selection of detection wavelength}

Each compound exhibited a different maximum UV absorbance. To detect ROS and NSAIDs sensitively, a wavelength program was performed along with the study at the isosbestic point of the wavelengths. The analysis was carried out at the isosbestic point $230 \mathrm{~nm}$ and the program was set at $240 \mathrm{~nm}$ (0-4.2 minutes), $361 \mathrm{~nm}$ (4.2-5.8 minutes), $230 \mathrm{~nm}$ (5.8-8.8 minutes), and $282 \mathrm{~nm}$ (8.8-13.2 minutes). For all API, pharmaceutical formulation, and human serum analyses, each drug was monitored at the isosbestic point and $\lambda_{\max }$ of each drug. Under these conditions, standard calibration curves showed good linearity $\left(\mathrm{r}^{2}=0.999\right)$, ranging from 0.025 to $2.500 \mu \mathrm{gmL}^{-1}$ for ROS, $0.1-10.0 \mu \mathrm{gmL}^{-1}$ for MEL, $0.0625-6.2500 \mu \mathrm{gmL}^{-1}$ for IBU, and $0.0375-3.7500 \mu \mathrm{gmL}^{-1}$ for MEF.

\section{Method validation}

The guidelines of the International Conference on Harmonisation of Technical Requirements for Registration of Pharmaceuticals for Human Use (ICH) ${ }^{44}$ and USP were followed for the validation of the optimized method. ${ }^{45-47}$

\section{Specificity and system suitability}

The good separation of analyte drugs observed in API and human serum chromatograms (Figure 3 ) shows the method is specific. There is no interfering peak of any additional components like excipients, degradation products or any interfering endogenous plasma components in serum samples. Excipients were spiked in samples to observe the additional peaks due to them, but no interfering peak is noticable in the chromatogram.

The uniformity of the system operation throughout the analysis was developed by initially equilibrating the system with ten consecutive injections of the mobile phase. The system suitability studies, as per ICH parameters, were found to be symmetrical in peaks. Theoretical plates, peak symmetry factor and tailing factor, resolution, and repeatability of the system were found favorable (Table 1).

\section{Linearity}

Calibration curves drawn for ten different concentrations by linear regression analysis showed good linearity with the correlation coefficient $\left(\mathrm{r}^{2}\right)>0.998$ and no significant variation in slopes and intercepts over the range of $0.1-2.5 \mu \mathrm{gmL}^{-1}$ for ROS, $0.4-10 \mu \mathrm{gmL}^{-1}$ for MEL, $0.25-6.25 \mu \mathrm{gmL}^{-1}$ for
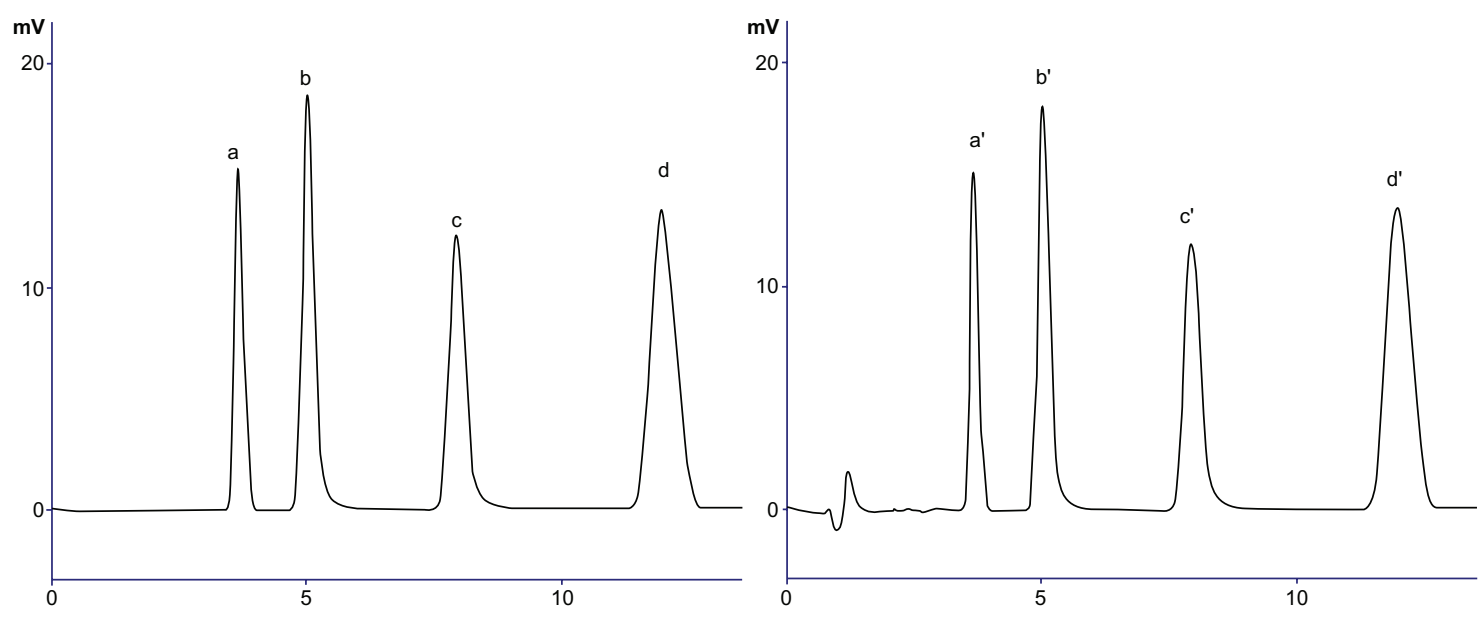

Figure 3 Representative chromatograms of rosuvastatin ( $a$ and $\left.a^{\prime}\right)$, meloxicam ( $b$ and $\left.b^{\prime}\right)$, ibuprofen ( $c$ and $\left.c^{\prime}\right)$ and mefenamic acid ( $d$ and $\left.d^{\prime}\right)$ in active pharmaceutical ingredient (left) and human serum (right), respectively. 
Table I System suitability parameters of rosuvastatin (ROS) and nonsteroidal anti-inflammatory drugs

\begin{tabular}{lccllll}
\hline Analytes & $\mathbf{t}_{\mathbf{R}}$ & $\mathbf{k}^{\prime}$ & $\mathbf{N}$ & $\mathbf{T}$ & $\mathbf{R s}$ & $\alpha$ \\
\hline \multicolumn{4}{l}{ At isosbestic point } \\
ROS & 3.52 & 0.54 & 1819 & - & - & 1.32 \\
MEL & 4.56 & 1.13 & 1933 & 0.99 & 3.48 & 2.09 \\
IBU & 7.73 & 2.39 & 2837 & 1.30 & 5.61 & 2.11 \\
MEF & 11.76 & 4.13 & 2669 & 1.57 & 5.36 & 1.73 \\
At individual & $\lambda_{\text {max }}$ & & & & & \\
ROS & 3.570 & 0.00 & 2268 & 1.58 & - & - \\
MEL & 4.887 & 0.37 & 2372 & 1.49 & 3.76 & 0.00 \\
IBU & 7.575 & 1.12 & 3100 & 1.46 & 5.69 & 3.04 \\
MEF & $I 1.334$ & 2.17 & 2358 & 1.71 & 5.09 & 1.94 \\
\hline
\end{tabular}

Abbreviations: $\alpha$, separation factor; IBU, ibuprofen; $\mathrm{k}^{\prime}$, capacity factors; MEF, mefenamic acid; MEL, meloxicam; $N$, theoretical plates; Rs, resolution; $t_{R}$, retention time; $\mathrm{T}$, tailing factor.

IBU, and 0.15-3.75 $\mu \mathrm{gmL}^{-1}$ for MEF. Results analyzed are tabulated in Table 2, with standard error, standard error of estimate, and slope showing the linear affiliation between concentration and peak areas.

\section{Accuracy}

The percentage recovery of the drugs was evaluated to be within the range of $99 \%-100.89 \%$ for the concentrations of
$80 \%, 100 \%$, and $120 \%$ of each drug. The results were found in accordance with the formulations and analytes spiked in human serum (Table 3) following the formula:

$$
\begin{aligned}
\text { Recovery }(\%)= & {[(\text { Measured concentration }} \\
& - \text { Original concentration }) \\
& / \text { Spiked concentration }] \times 100
\end{aligned}
$$

\section{Precision}

The repeatability of the method confirmed its precision. Six concentrations were analyzed for 3 days for inter-day precision. The statistical summary comprises coefficients of variance (relative standard deviation $[\% \mathrm{RSD}]<2$ ) and recoveries (99\%-100.89\%; Table 4).

\section{Detection and quantification limit}

The sensitivity of the method was analyzed from the slope of the calibration curve and standard deviation was used to calculate the limits of quantification and detection; as a result LOQ was greater than 9 and less than 23, while LOD was greater than 3

\begin{tabular}{|c|c|c|c|c|c|c|c|c|}
\hline \multirow[t]{2}{*}{ Parameter } & \multicolumn{4}{|c|}{ At isosbestic point } & \multicolumn{4}{|c|}{ At individual $\lambda_{\max }$} \\
\hline & ROS & MEL & IBU & MEF & ROS & MEL & IBU & MEF \\
\hline \multicolumn{9}{|c|}{ Active pharmaceutical ingredient } \\
\hline Conc $\left(\mu g m L^{-1}\right)$ & $0.1-2.5$ & $0.4-10$ & $0.25-6.25$ & $0.15-3.75$ & $0.025-2.5$ & $0.1-10$ & $0.0625-6.25$ & $0.0375-3.75$ \\
\hline Slope & 16507 & 51076 & 73944 & 23345 & 40106 & 16203 & 19563 & 42294 \\
\hline Intercept & -3405 & 19674 & 18733 & 9383 & 2614 & 5034 & 7085 & 2722 \\
\hline LOD $\left(\mathrm{ngmL}^{-1}\right)$ & 3 & 5 & 4 & 7 & 1 & 2 & I & 4 \\
\hline LOQ (ngmL $\left.{ }^{-1}\right)$ & 9 & 14 & 13 & 23 & 4 & 7 & 3 & 11 \\
\hline$r^{2}$ & 0.9992 & 0.9997 & 0.9997 & 0.9993 & 0.9996 & 0.9993 & 0.998 & 0.9993 \\
\hline SEE & 17062 & $|558|$ & 9925 & 21321 & 14954 & 29462 & 15545 & 27001 \\
\hline SE & 9744 & 8899 & 5668 & 12177 & 7480 & 14737 & 8878 & 13506 \\
\hline \multicolumn{9}{|l|}{ Serum } \\
\hline Conc $\left(\mu g m L^{-1}\right)$ & $0.1-2.5$ & $0.4-10$ & $0.25-6.25$ & $0.15-3.75$ & $0.025-2.5$ & $0.1-10$ & $0.0625-6.25$ & $0.0375-3.75$ \\
\hline Slope & 16497 & $49 \mid 28$ & 76452 & 23393 & 43243 & 26203 & 26715 & 33108 \\
\hline Intercept & -1913 & 35695 & 5656 & 8823 & 10630 & 30516 & 39485 & 25703 \\
\hline LOD $\left(\mathrm{ngmL}^{-1}\right)$ & 6 & 8 & 6 & 1 & 3 & 2 & 4 & I \\
\hline LOQ (ngmL $\left.{ }^{-1}\right)$ & 17 & 23 & 19 & 4 & 10 & 6 & 12 & 3 \\
\hline$r^{2}$ & & & & & 0.999 & 0.998 & 0.998 & 0.999 \\
\hline SEE & 16515 & 15545 & 10067 & 21508 & 24866 & 27001 & 30380 & 35709 \\
\hline SE & 94312 & 8878 & 5749 & 12284 & 12438 & 13506 & 15196 & 17862 \\
\hline \multicolumn{9}{|c|}{ Pharmaceutical formulations (tablets) } \\
\hline Conc $\left(\mu g m L^{-1}\right)$ & $0.1-2.5$ & $0.4-10$ & $0.25-6.25$ & $0.15-3.75$ & $0.025-2.5$ & $0.1-10$ & $0.0625-6.25$ & $0.0375-3.75$ \\
\hline Slope & $16559 \mid$ & 52083 & 75467 & 234264 & 42977 & 26650 & 26814 & 33746 \\
\hline Intercept & -4129.2 & 6652.7 & 12297 & 7983 & 1979| & 28544 & 37886 & 25610 \\
\hline LOD $\left(\mathrm{ngmL}^{-1}\right)$ & 11 & 4 & 5 & 4 & 2 & 3 & 2 & 3 \\
\hline LOQ $\left(\mathrm{ngmL}^{-1}\right)$ & 34 & 11 & 14 & 11 & 7 & 10 & 6 & 9 \\
\hline$r^{2}$ & 0.9997 & 0.9988 & 0.998 & 0.9994 & 0.998 & 0.998 & 0.998 & 0.999 \\
\hline SEE & 16993 & 20547 & 10040 & 24378 & $2257 \mid$ & 26566 & 25012 & 31711 \\
\hline $\mathrm{SE}$ & 9705 & 11735 & 5734 & 13923 & 10709 & 12604 & 11867 & 15045 \\
\hline
\end{tabular}
and less than 7 ngmL-1 for all drug analytes in API (Table 2).

Table 2 Regression statistics of rosuvastatin (ROS) and nonsteroidal anti-inflammatory drugs

Abbreviations: conc, concentration; IBU, ibuprofen; LOD, limit of detection; LOQ, limit of quantification; MEF, mefenamic acid; MEL, meloxicam; SE, standard error; SEE, standard error of estimate. 
Table 3 Accuracy and recovery studies of rosuvastatin (ROS) and nonsteroidal anti-inflammatory drugs

\begin{tabular}{|c|c|c|c|c|c|c|}
\hline \multirow[t]{3}{*}{ Conc $\%$} & \multicolumn{6}{|l|}{$\%$ rec } \\
\hline & \multicolumn{3}{|c|}{ At isosbestic point } & \multicolumn{3}{|c|}{ At individual $\lambda_{\max }$} \\
\hline & API & Tablet & Serum & API & Tablet & Serum \\
\hline \multicolumn{7}{|l|}{ ROS } \\
\hline 80 & 99.99 & 100.03 & 99.32 & 99.97 & 97.60 & 97.52 \\
\hline 100 & 100.03 & 100.03 & 100.49 & 99.98 & 105.73 & 104.09 \\
\hline 120 & 100.00 & 100.05 & 99.582 & 99.94 & 100.91 & 100.28 \\
\hline \multicolumn{7}{|c|}{ Meloxicam } \\
\hline 80 & 100.02 & 99.88 & 99.89 & 100.01 & 98.43 & 97.69 \\
\hline 100 & 100.00 & 100.09 & 100.01 & 100.05 & 96.49 & 96.63 \\
\hline 120 & 100.02 & 99.97 & 99.971 & 99.95 & 90.99 & 91.20 \\
\hline \multicolumn{7}{|c|}{ Ibuprofen } \\
\hline 80 & 99.97 & 100.03 & 100.07 & 99.99 & 103.30 & 101.42 \\
\hline 100 & 100.03 & 100.05 & 99.90 & 100.10 & 110.92 & 106.94 \\
\hline 120 & 100.01 & 99.95 & 100.01 & 100.14 & 110.88 & 103.99 \\
\hline \multicolumn{7}{|c|}{ Mefenamic acid } \\
\hline 80 & 99.84 & 100.00 & 100.28 & 99.88 & 99.50 & 96.14 \\
\hline 100 & 100.00 & 99.94 & 99.96 & 100.06 & 104.71 & 101.17 \\
\hline 120 & 99.99 & 99.95 & 100.02 & 99.79 & 102.39 & 103.62 \\
\hline
\end{tabular}

Abbreviations: API, active pharmaceutical ingredient; conc, concentration; rec, recovery.

Table 4 Inter-day precision studies of rosuvastatin and nonsteroidal anti-inflammatory drugs

\begin{tabular}{|c|c|c|c|c|c|c|c|c|c|}
\hline \multirow[t]{2}{*}{ Conc $\mu \mathrm{gmL}^{-1}$} & \multicolumn{9}{|c|}{ \%RSD } \\
\hline & \multicolumn{3}{|l|}{ API } & \multicolumn{2}{|l|}{ Tablet } & \multicolumn{3}{|l|}{ Serum } & \multirow[t]{2}{*}{ API at individual $\lambda_{\text {max }}$} \\
\hline Rosuvastatin & & & & & & & & & \\
\hline 0.1 & 0.28 & 0.10 & 0.09 & 0.20 & 0.08 & 0.44 & 0.05 & 0.13 & 0.22 \\
\hline 0.3 & 0.11 & 0.01 & 0.10 & 0.16 & 0.01 & 0.07 & 0.17 & 0.03 & 0.30 \\
\hline 0.6 & 0.26 & 0.01 & 0.34 & 1.08 & 0.07 & 0.05 & 0.51 & 0.12 & 0.32 \\
\hline 0.9 & 0.66 & 0.01 & 0.11 & 0.13 & 0.01 & 0.04 & 0.06 & 0.42 & 0.07 \\
\hline 1.5 & 0.16 & 0.01 & 0.11 & 0.00 & 0.02 & 0.10 & 0.03 & 0.19 & 0.01 \\
\hline 2.5 & 0.04 & 0.03 & 0.02 & 0.03 & 0.09 & 0.05 & 0.70 & 0.09 & 0.32 \\
\hline \multicolumn{10}{|l|}{ Meloxicam } \\
\hline 0.4 & 0.06 & 0.27 & 0.16 & 0.20 & 0.35 & 0.440 & 0.23 & 0.45 & 0.04 \\
\hline 1.2 & 0.01 & 0.06 & 0.02 & 0.165 & 0.31 & 0.073 & 0.52 & 0.10 & 0.07 \\
\hline 2.4 & 0.05 & 0.17 & 0.01 & 1.079 & 0.34 & 0.051 & 0.61 & 0.07 & 0.04 \\
\hline 3.6 & 0.03 & 0.04 & 0.04 & 0.127 & 0.05 & 0.040 & 0.11 & 0.03 & 0.06 \\
\hline 6 & 0.01 & 0.94 & 0.01 & 0.001 & 0.04 & 0.099 & 0.03 & 0.10 & 0.02 \\
\hline 10 & 0.02 & 0.04 & 0.01 & 0.001 & 0.01 & 0.055 & 0.05 & 0.04 & 0.05 \\
\hline \multicolumn{10}{|l|}{ Ibuprofen } \\
\hline 0.25 & 0.04 & 0.50 & 0.74 & 0.53 & 0.77 & 0.70 & 0.60 & 0.60 & 0.06 \\
\hline 0.75 & 0.08 & 0.04 & 0.05 & 0.13 & 0.06 & 0.77 & 0.06 & 0.75 & 0.12 \\
\hline 1.5 & 0.09 & 0.04 & 0.06 & 0.16 & 0.50 & 0.36 & 0.50 & 0.38 & 0.06 \\
\hline 2.25 & 0.21 & 0.02 & 0.04 & 0.08 & 0.02 & 0.02 & 0.02 & 0.18 & 0.21 \\
\hline 3.75 & 0.05 & 0.19 & 0.15 & 0.03 & 0.01 & 0.06 & 0.01 & 0.02 & 0.13 \\
\hline 6.25 & 0.01 & 0.02 & 0.08 & 0.01 & 0.07 & 0.02 & 0.01 & 0.06 & 0.01 \\
\hline \multicolumn{10}{|c|}{ Mefenamic acid } \\
\hline 0.15 & 0.69 & 0.15 & 0.03 & 0.02 & 0.51 & 0.03 & 0.51 & 0.06 & 0.08 \\
\hline 0.45 & 0.23 & 0.10 & 0.05 & 0.03 & 0.07 & 1.06 & 0.07 & 0.49 & 0.11 \\
\hline 0.9 & 0.54 & 0.01 & 0.03 & 0.27 & 0.11 & 0.08 & 0.17 & 0.11 & 0.02 \\
\hline 1.35 & 0.13 & 0.00 & 0.11 & 0.07 & 0.03 & 0.04 & 0.03 & 0.41 & 0.29 \\
\hline 2.25 & 0.01 & 0.09 & 0.03 & 0.02 & 0.20 & 0.77 & 0.21 & 0.04 & 0.04 \\
\hline 3.75 & 0.22 & 0.09 & 0.01 & 0.03 & 0.01 & 0.08 & 0.04 & 0.10 & 0.11 \\
\hline
\end{tabular}

Abbreviations: API, active pharmaceutical ingredient; conc, concentration; \%RSD, relative standard deviation. 
Table 5 Robustness and ruggedness studies of rosuvastatin and nonsteroidal anti-inflammatory drugs

\begin{tabular}{|c|c|c|c|c|}
\hline & Parameters & $\mathbf{t}_{\mathrm{R}}$ & $\mathbf{N}$ & $\mathbf{T}$ \\
\hline \multicolumn{5}{|l|}{ Rosuvastatin } \\
\hline \multirow[t]{3}{*}{$\mathrm{pH}$} & 2.9 & 3.637 & 2068 & 1.76 \\
\hline & 3 & 3.83 & 2352 & 1.85 \\
\hline & 3.1 & 3.62 & 2205 & 1.55 \\
\hline Flow rate & 0.9 & 3.95 & 2316 & 1.45 \\
\hline \multirow[t]{2}{*}{$\left(\mathrm{mL} / \mathrm{min}^{-1}\right)$} & I & 3.83 & 2352 & 1.85 \\
\hline & 1.1 & 3.71 & 2397 & 1.25 \\
\hline Mobile phase & $78 / 19.5 / 2.5$ & 3.64 & 2162 & 1.54 \\
\hline \multirow[t]{2}{*}{$(\mathrm{v} / \mathrm{v} / \mathrm{v})$} & $80 / 17.5 / 2.5$ & 3.83 & 2352 & 1.85 \\
\hline & $82 / 15.5 / 2.5$ & 3.62 & 2175 & 1.58 \\
\hline \multirow[t]{2}{*}{ Column } & Purospher ${ }^{\circledR}$ STAR $C_{18}$ & 3.83 & 2352 & 1.85 \\
\hline & Sapilco ${ }^{\circledast} \mathrm{C}_{18}$ & $3.64 I$ & 2172 & 1.55 \\
\hline \multirow[t]{2}{*}{ System } & LC-20AT & 3.83 & 2352 & 1.85 \\
\hline & LC-IOAT & 3.568 & 2399 & $1.5 \mathrm{I}$ \\
\hline \multicolumn{5}{|l|}{ Meloxicam } \\
\hline \multirow[t]{3}{*}{$\mathrm{pH}$} & 2.9 & 4.99 & 2282 & 1.33 \\
\hline & 3 & 5.79 & 2398 & 1.57 \\
\hline & 3.1 & 4.97 & 2321 & 1.42 \\
\hline Flow rate & 0.9 & 5.86 & 2412 & 1.54 \\
\hline \multirow[t]{2}{*}{$\left(\mathrm{mL} / \mathrm{min}^{-1}\right)$} & 1 & 5.79 & 2398 & 1.57 \\
\hline & I.I & 5.60 & 2389 & 1.56 \\
\hline Mobile phase & $78 / 19.5 / 2.5$ & 4.99 & 2193 & 0.47 \\
\hline \multirow[t]{2}{*}{$(v / v / v)$} & $80 / 17.5 / 2.5$ & 5.79 & 2398 & 1.57 \\
\hline & $82 / 15.5 / 2.5$ & 4.95 & 2194 & 1.48 \\
\hline \multirow[t]{2}{*}{ Column } & Purospher STAR $C_{18}$ & 5.79 & 2398 & 1.57 \\
\hline & Sapilco $C_{18}$ & 5.002 & 2304 & 1.39 \\
\hline \multirow[t]{2}{*}{ System } & LC-20AT & 5.79 & 2398 & 1.57 \\
\hline & LC-IOAT & 4.853 & 2486 & 1.41 \\
\hline \multicolumn{5}{|l|}{ Ibuprofen } \\
\hline \multirow[t]{3}{*}{$\mathrm{Ph}$} & 2.9 & 7.91 & 3046 & 1.32 \\
\hline & 3 & 7.01 & 3100 & 1.56 \\
\hline & 3.1 & 7.89 & 2986 & 1.35 \\
\hline Flow rate & 0.9 & 7.11 & 3125 & 1.57 \\
\hline \multirow[t]{2}{*}{$\left(\mathrm{mL} / \mathrm{min}^{-1}\right)$} & 1 & 7.01 & 3100 & 1.56 \\
\hline & I.I & 6.91 & 3091 & 1.44 \\
\hline Mobile phase & $78 / 19.5 / 2.5$ & 7.85 & 2966 & 1.38 \\
\hline \multirow[t]{2}{*}{$(v / v / v)$} & $80 / 17.5 / 2.5$ & 7.01 & 3100 & 1.56 \\
\hline & $82 / 15.5 / 2.5$ & 7.808 & 2978 & 1.27 \\
\hline \multirow[t]{2}{*}{ Column } & Purospher STAR $C_{18}$ & 7.01 & 3100 & 1.56 \\
\hline & Sapilco $C_{18}$ & 7.933 & 3018 & 1.30 \\
\hline \multirow[t]{2}{*}{ System } & LC-20AT & 7.01 & 3100 & 1.56 \\
\hline & LC-IOAT & 7.58 & 3251 & 1.39 \\
\hline Mefenamic a & & & & \\
\hline $\mathrm{pH}$ & 2.9 & 11.95 & 2793 & 1.61 \\
\hline & 3 & 11.34 & 2778 & 1.58 \\
\hline & 3.1 & 11.99 & 2763 & 1.65 \\
\hline Flow rate & 0.9 & $|I .5|$ & 2784 & $1.5 \mathrm{I}$ \\
\hline$\left(\mathrm{mL} / \mathrm{min}^{-1}\right)$ & 1 & 11.34 & 2778 & 1.58 \\
\hline & I.I & 11.52 & 2764 & $1.4 \mathrm{I}$ \\
\hline Mobile phase & $78 / 19.5 / 2.5$ & II.87 & 2743 & 1.67 \\
\hline$(v / v / v)$ & $80 / 17.5 / 2.5$ & 11.34 & 2778 & 1.58 \\
\hline & $82 / 15.5 / 2.5$ & 11.75 & 2736 & 1.67 \\
\hline Column & Purospher STAR $\mathrm{C}_{18}$ & 11.34 & 2778 & 1.58 \\
\hline & Sapilco $C_{18}$ & 11.33 & 2430 & 1.63 \\
\hline System & LC-20AT & 11.34 & 2778 & 1.58 \\
\hline & LC-IOAT & 11.16 & 2893 & $\mathrm{I} .77$ \\
\hline
\end{tabular}

Abbreviations: $\mathrm{T}$, tailing factor; $\mathrm{t}_{\mathrm{R}}$, retention time; $\mathrm{N}$, theoretical plates.

\section{Ruggedness}

The analysis of the method was carried out in different laboratories and with different instruments at the Research Institute of Pharmaceutical Sciences and HEC laboratory Chemistry Department, both at the University of Karachi, to determine the reproducibility of the method. ${ }^{48,49}$ The instruments used at the two laboratories were the LC-10AT and LC-20AT, used at the Research Institute of Pharmaceutical Sciences and HEC laboratory Chemistry Department, respectively. The results obtained on different days with different drug samples show an acceptable range of variation on the two instruments. Data acquisition was compared on the Purospher STAR $_{18}(5 \mu \mathrm{m}, 250 \times 0.46 \mathrm{~cm})$ and Sapilco $\mathrm{C}_{18}(5 \mu \mathrm{m}$, $250 \times 0.46 \mathrm{~cm})$ columns. This shows suitability of all the analytes in the method developed (Table 5).

\section{Robustness}

Robustness studies were carried out to measure the method's capacity to remain unaffected by small but deliberate variations in parameters by varying the mobile phase ratio $\pm 2 \%$, flow rate $\pm 0.1 \%$, and $\mathrm{pH} \pm 0.1 \%$ from their optimum conditions. Changing only one parameter resulted in column and system suitability parameters that did not exceed $2 \%$, showing that the method is reliable under normal usage (Table 5).

\section{Determination of ROS and NSAIDs in pharmaceutical formulations}

The accuracy of the proposed method was evaluated by recovery assays made on the formulation samples. Thus, known

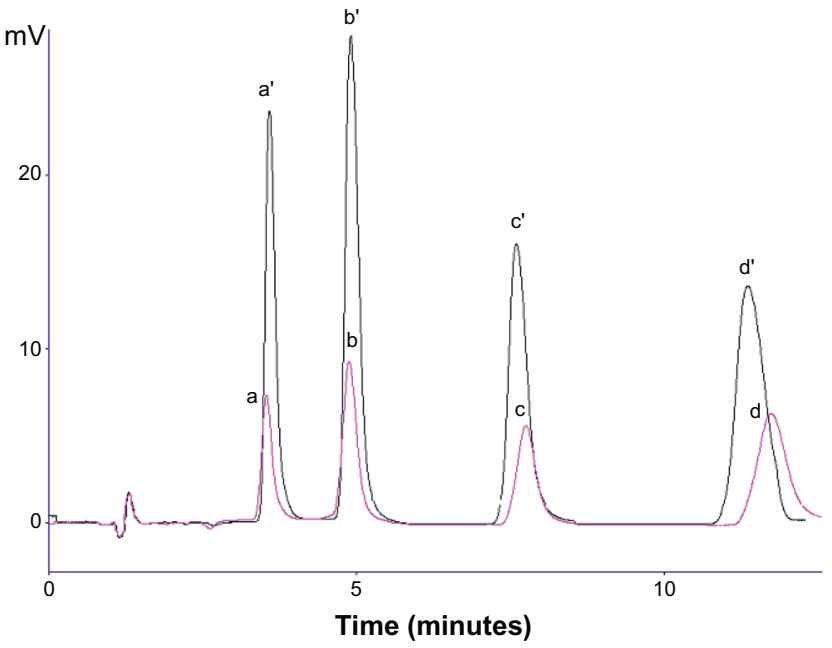

Figure 4 Representative chromatograms of rosuvastatin ( $a$ and $a^{\prime}$ ), meloxicam (b and $b^{\prime}$ ), ibuprofen (c and $c^{\prime}$ ) and mefenamic acid ( $d$ and $d^{\prime}$ ) at isosbestic point and individual wavelength maxima, respectively. 


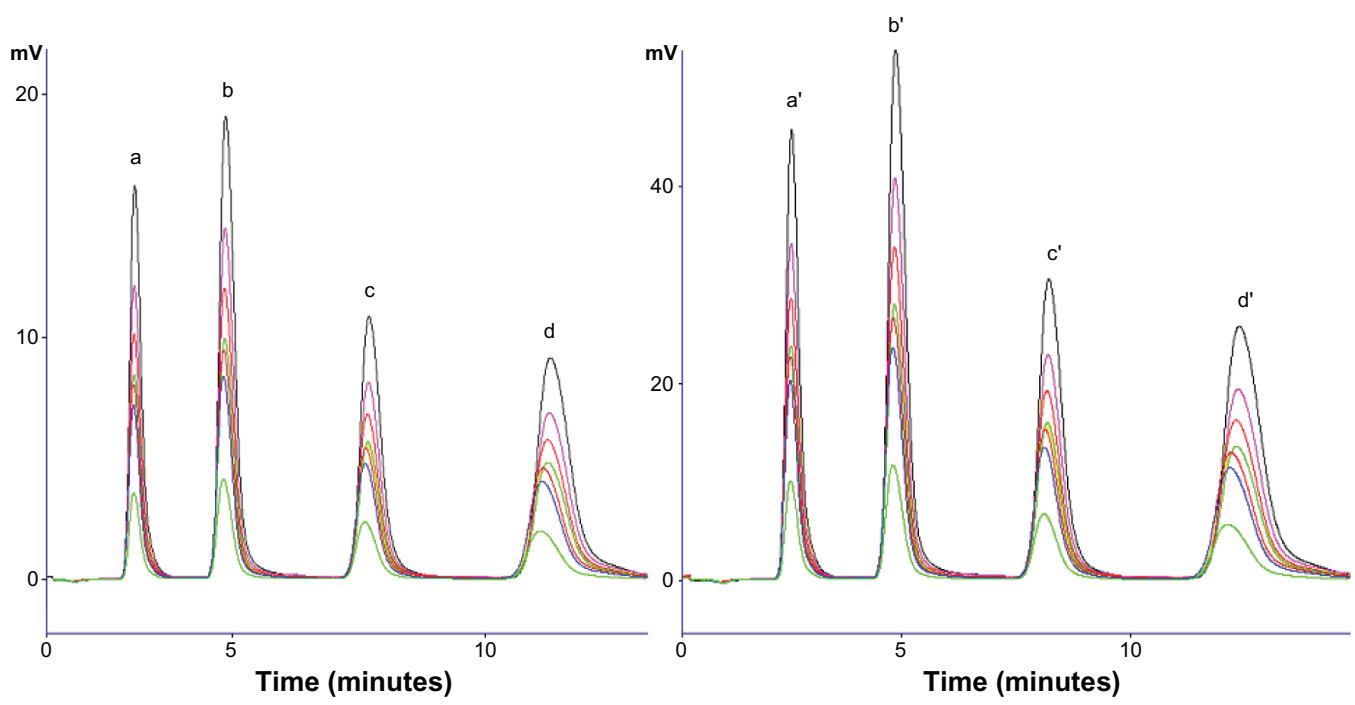

Figure 5 Representative chromatograms of comparison of linearity of rosuvastatin (a and $\left.a^{\prime}\right)$, meloxicam (b and $\left.b^{\prime}\right)$, ibuprofen (c and $\left.c^{\prime}\right)$ and mefenamic acid ( $d$ and $\left.d^{\prime}\right)$ at isosbestic point (left) and individual wavelength maxima (right), respectively.

amounts of each compound were added to the corresponding formulations at three levels of concentration $(80 \%, 100 \%$, and $120 \%$; Table 3 ).

The precision of the proposed method was performed by adding each compound to the selected formulation on different days. The precision $(\% \mathrm{RSD})$ for all the studied components in different dosage forms was $<2 \%$ for the inter-day assay for all drugs (Table 4).

\section{Determination of ROS and NSAIDs in human serum}

The calibration curves were prepared over the concentration range of $0.1-2.5 \mu \mathrm{gmL}^{-1}$ for ROS, $0.4-10 \mu \mathrm{gmL}^{-1}$ for MEL, 0.25-6.25 $\mu \mathrm{gmL}^{-1}$ for IBU, and 0.15-3.75 $\mu \mathrm{gmL}^{-1}$ for MEF in human serum by assaying in triplicate at eight different concentrations. As shown in Table 2, the calibration curves were linear over the spiked range for each compound with a good correlation coefficient $\left(\mathrm{r}^{2}>0.999\right)$. The method was sensitive to $4<$ LOQs $<17$ and $1<$ LODs $<6 \mathrm{ngmL}^{-1}$ in serum (Figure 3).

Assessment of the inter-day accuracy and precision of the method was performed in drug-free serum samples spiked with ROS (range of 0.1-2.5 $\mathrm{gmL}^{-1}$ ), MEL (0.4-10.0 $\mu \mathrm{gmL}^{-}$ $\left.{ }^{1}\right)$, IBU (0.25-6.25 $\left.\mu \mathrm{gmL}^{-1}\right)$, and $\operatorname{MEF}\left(0.15-3.75 \mu \mathrm{gmL}^{-1}\right)$. For the inter-day precision analysis, the spiked serum was studied at the same concentration of each drug on three different days. Precision is shown as \%RSD and accuracy as percent recovery value (Equation 1) and these are presented in Tables 3 and 2 , respectively. Precision was observed to be $<2 \%$ for all drugs spiked at all concentrations and assay accuracy was found to be $99.30 \%-100.89 \%$ for all compounds.

\section{Analysis under program detector}

The programming of the HPLC detector according to the $\lambda_{\text {max }}$ of each analyte during simultaneous determination has been found informative and useful for routine analysis and special cases in which the sample contains analytes in amounts that can be measured in quantities as small as nanograms.

The linearity curves obtained for the same concentration range optimized for the method showed clear gaps in the respective peak heights and, thus, peak areas of the analytes. Figure 4 shows a comparison of the peak heights of the chromatograms of same concentration of analytes in human serum recorded at isosbestic point and when the detector was programmed. The calibration curves were linear, with $\mathrm{r}^{2}>0.998$ shown in Table 2. The upper limit of the analytes for ROS $2.5 \mu \mathrm{gmL}^{-1}$, MEL $10 \mu \mathrm{gmL}^{-1}$; IBU $6.25 \mu \mathrm{gmL}^{-1}$, and MEF $3.75 \mu \mathrm{gmL}^{-1}$ shifted above $100 \mathrm{mV}$ from the peaks below $100 \mathrm{mV}$, so the lower limit of the concentration range shifted down from 0.1 to $0.025 \mu \mathrm{gmL}^{-1}$ for ROS, from 0.4 to $0.1 \mu \mathrm{gmL}^{-1}$ for MEL; from 0.25 to $0.0625 \mu \mathrm{gmL}^{-1}$ for IBU, and from 0.15 to $0.0375 \mu \mathrm{gmL}^{-1}$ for MEF.

The LOD values made the method sensitive for ROS, MEL, IBU, and MEF to quantifiable limits of the drugs: $4<\mathrm{LOQ}<11$ and $1<\mathrm{LOD}<4 \mathrm{ngmL}^{-1}$ for API and $3<\mathrm{LOQ}<10$ and $1<\mathrm{LOD}<3 \mathrm{ngmL}^{-1}$ for human serum - these can be seen in Table 2 . The linear corresponding behavior of the analytes according to both measurement techniques is shown in Figure 5.

To test the accuracy and precision of this technique, the corresponding criteria of validation were applied. The $\%$ RSD $<2$ and percent recoveries within the range of $97.6 \%$ $106.9 \%$ showed it to be precise and accurate (comparison 
is shown in Tables 3 and 4). There were no significant differences in the results of both practices for system suitability parameters for the system shown in Table 1 .

The method was found specific for the drugs from their excipients and foreign materials, even when the results were amplified. This technique was found equally possible for API, tablet formulations, and serum samples.

\section{Conclusion}

A simple and sensitive HPLC-UV detection method for the simultaneous determination of ROS and NSAIDs (MEL, IBU, and MEF) was developed. The proposed method was successfully applied to the determination of these NSAIDs in pharmaceutical formulations as well as in human plasma samples. The LODs of each compound in human plasma were as low as $1-6 \mathrm{ngmL}^{-1}$ at a signalto-noise ratio of 3 , which was sufficient for monitoring the plasma concentrations of each compound. In addition, the sensitivity of the proposed method increased when compared with the analysis at the programmed $\lambda_{\max }$ of each drug. The detection limits reached $1-3 \mathrm{ngmL}^{-1}$ for all the drug analytes.

The low limits of detection and quantification in pharmaceuticals and serum make the method applicable to quantification of the drug in quality control analysis, forensic medicine, clinical laboratories, and raw materials.

\section{Disclosure}

The authors declare no conflicts of interest in this work.

\section{References}

1. Niddam-Hildesheim V, Sterimbaum G, inventors; Teva Pharmaceutical Industries Ltd, assignee. Process for preparation of rosuvastatin calcium. United States patent US 7396927. July 8, 2008.

2. McKenney JM. Efficacy and safety of rosuvastatin in treatment of dyslipidemia. Am J Health Syst Pharm. 2005;62(10):1033-1047.

3. Caslake MJ, Stewart G, Day SP, et al. Phenotype-dependent and -independent actions of rosuvastatin on atherogenic lipoprotein subfractions in hyperlipidaemia. Atherosclerosis. 2003;171(2):245-253.

4. Lan K, Jiang X, Li Y, et al. Quantitative determination of rosuvastatin in human plasma by ion pair liquid-liquid extraction using liquid chromatography with electrospray ionization tandem mass spectrometry. J Pharm Biomed Anal. 2007;44(2):540-546.

5. Kumar TR, Shitut NR, Kumar PK, et al. Determination of rosuvastatin in rat plasma by HPLC: Validation and its application to pharmacokinetic studies. Biomed Chromatogr. 2006;20(9):881-887.

6. Sane RT, Kamat SS, Menon SN, Inamdar SR, Mote MR. Determination of rosuvastatin calcium in its bulk drug and pharmaceutical preparations by high-performance thin-layer chromatography. Journal of Planar Chromatography. 2005;18(103):194-198.

7. Chaudhari BG, Patel NM, Shah PB. Determination of simvastatin, pravastatin sodium and rosuvastatin calcium in tablet dosage forms by HPTLC. Indian J Pharm Sci. 2007;69(1):130-132.
8. Pasha MK, Muzeeb S, Basha SJ, Shashikumar D, Mullangi R, Srinivas NR. Analysis of five HMG-CoA reductase inhibitors - atorvastatin, lovastatin, pravastatin, rosuvastatin and simvastatin: pharmacological, pharmacokinetic and analytical overview and development of a new method for use in pharmaceutical formulations analysis and in vitro metabolism studies. Biomed Chromatogr. 2006;20(3):282-293.

9. Sultana N, Arayne MS, Iftikhar B. Simultaneous determination of atenolol, rosuvastatin, spironolactone, glibenclamide and naproxen sodium in pharmaceutical formulations and human plasma by RP-HPLC. Journal of the Chinese Chemical Society. 2008;55(5): 1022-1029.

10. Arayne MS, Sultana N, Mirza AZ, Shamshad H. High-performance liquid chromatographic analysis of pioglitazone, gliquidone, rosuvastatin and simvastatin in formulations and human serum. Chinese Journal of Chemistry. 2010;28(10):1998-2002.

11. Sultana N, Arayne MS, Shahzad W. Simultaneous determination of ceftriaxone sodium and statin drugs in pharmaceutical formulations and human serum by RP-HPLC. Journal of the Chilean Chemical Society. 2010;55(2):193-198.

12. Sultana N, Arayne MS, Shafi N, Siddiqui FA, Hussain A. Development of a RP-HPLC method for the simultaneous analysis of diltiazem and statin: Application in pharmaceuticals and human serum. Anal Methods. 2010;2(10):1571-1576

13. Sultana N, Arayne MS, Naveed S. Validated method for the simultaneous determination of lisinopril, pravastatin, atorvastatin and rosuvastatin in API, formulations and human serum by RP-HPLC. Chinese Journal of Chemistry. 2011;29(6):1216-1220.

14. Sultana N, Arayne MS, Naveed S. Simultaneous determination of captopril and statins in API, pharmaceutical formulations and in human serum by RP-HPLC. Journal of the Chinese Chemical Society. 2010;57(3A):378-383.

15. Arayne MS, Sultana N, Tabassum A, Ali SN, Naveed S. Simultaneous LC determination of rosuvastatin, lisinopril, captopril, and enalapril in API, pharmaceutical dosage formulations, and human serum. Med Chem Res. 2012;19(7). Abstract.

16. Chmielewska A, Konieczna L, Plenis A, Bieniecki M, Lamparczyk H. Determination of diclofenac in plasma by high-performance liquid chromatography with electrochemical detection. Biomed Chromatogr. 2006;20(1):119-124.

17. Sajeev C, Jadhav PR, RaviShankar D, Saha RN. Determination of flurbiprofen in pharmaceutical formulations by UV spectrophotometry and liquid chromatography. Anal Chim Acta. 2002;463(2): 207-217.

18. Stafiej A, Pyrzynska K, Regan F. Determination of anti-inflammatory drugs and estrogens in water by HPLC with UV detection. $J$ Sep Sci. 2007;30(7):985-991.

19. Madni AU, Ahmad M, Akhtar N, Usman M. New simultaneous high performance liquid chromatographic method for determination of NSAIDs and opioid analgesics in advanced drug delivery systems and human plasma. World Acad Sci Eng Technol. 2009;55: $158-163$.

20. Kang SH, Chang SY, Do KC, Chi SC, Chung DS. High-performance liquid chromatography with a column-switching system and capillary electrophoresis for the determination of ibuprofen in plasma. J Chromatogr B Biomed Sci Appl. 1998;712(1-2):153-160.

21. Canaparo R, Muntoni E, Zara GP, et al. Determination of Ibuprofen in human plasma by high-performance liquid chromatography: validation and application in pharmacokinetic study. Biomed Chromatogr. 2000;14(4):219-226.

22. Vermeulen B, Remon JP. Validation of a high-performance liquid chromatographic method for the determination of ibuprofen enantiomers in plasma of broiler chickens. J Chromatogr B Biomed Sci Appl. 2000;749(2):241-243.

23. Farrar H, Letzig L, Gill M. Validation of a liquid chromatographic method for the determination of ibuprofen in human plasma. $J$ Chromatogr $B$ Analyt Technol Biomed Life Sci. 2002;780(2):341-348. 
24. Whelan MR, Ford JL, Powell MW. Simultaneous determination of ibuprofen and hydroxypropylmethylcellulose (HPMC) using HPLC and evaporative light scattering detection. J Pharm Biomed Anal. 30(4):1355-1359.

25. Quagila MG, Donati E, Fanali S, Catarcini P. Ibuprofen quality control by electrochromatography. Farmaco. 2003;58(9):699-705.

26. Makino K, Itoh Y, Teshima D, Oishi R. Determination of nonsteroidal anti-inflammatory drugs in human specimens by capillary zone electrophoresis and micellar electrokinetic chromatography. Electrophoresis. 2004;25(10-11):1488-1495.

27. Bonato PS, Del Lama MP, de Carvalho R. Enantioselective determination of ibuprofen in plasma by high-performance liquid chromatography-electrospray mass spectrometry. J Chromatogr B Analyt Technol Biomed Life Sci. 2003;796(2):413-420.

28. Velpandian T, Jaiswal J, Bhardwaj RK, Gupta SK. Development and validation of a new high-performance liquid chromatographic estimation method of meloxicam in biological samples. J Chromatogr B Biomed Sci Appl. 2000;738(2):431-436.

29. Dasandi B, Shivaprakash, Saroj H, Bhat KM. LC determination and pharmacokinetics of meloxicam. J Pharm Biomed Anal. 2002;28(5):999-1004.

30. Baeyens WR, Van der Weken G, D'haeninck E, et al. Application of an alkyldiol silica precolumn in a column-switching system for the determination of meloxicam in plasma. $J$ Pharm Biomed Anal. 2003;32(4-5):839-846.

31. Zawilla NH, Abdul-Azim Mohammad M, El kousy NM, El-Moghazy Aly SM. Determination of meloxicam in bulk and pharmaceutical formulations. J Pharm Biomed Anal. 2003;32(6):1135-1144.

32. Arayne MS, Sultana N, Siddiqui FA. A new RP-HPLC method for analysis of meloxicam in tablets. Pak J Pharm Sci. 2005;18(1):58-62.

33. Wahab SU, Firthouse PU, Halith SM, Chandran M, Mohideen SS. Development of RP-HPLC method for the simultaneous determination of mefenamic acid and drotaverine $\mathrm{HCl}$ combined tablet dosage form. International Journal of Pharmaceutical Sciences. 2011;3(1):115-117.

34. Dahivelkar PP, Bari SB, Bhoir S, Bhagwat AM. High performance liquid chromatographic estimation of drotaverine hydrochloride and mefenamic acid in human plasma. Iranian Journal of Pharmaceutical Research. 2009;8(3):209-215.

35. Jaiswal Y, Talele G, Surana S. Application of HPLC for the simultaneous determination of ethamsylate and mefenamic acid in bulk drugs and tablets. J Liq Chromatogr Relat Technol. 2007;30(8):1115-1124.

36. Natesan S, Thanasekaran D, Krishnaswami V, Ponnusamy C. Improved RP-HPLC method for the simultaneous estimation of tranexamic acid and mefenamic acid in tablet dosage form. Pharm Anal Acta. 2011;2:115.

37. Sultana N, Arayne MS, Siddiqui R, Naveed S. RP-HPLC method for the simultaneous determination of lisinopril and NSAIDs in API, pharmaceutical formulations and human serum. J Am Chem Soc. 2012;3:147-152.
38. Gul S, Sultana N, Arayne MS, Shamim S, Akhtar M. New method for optimization and simultaneous determination of sparfloxacin and non steroidal anti-inflammatory drugs: its in-vitro application. $J \mathrm{Am}$ Chem Soc. 2012;3:328-337.

39. Arayne MS, Sultana N, Zuberi MH, Haroon U. In vitro studies of interaction between metformin and NSAIDS (non steroidal antiinflamatory drugs) using spectrophotometry and RP-high performance liquid chromatography. Journal of the Chilean Chemical Society. 2010;55(2):206-211.

40. Arayne MS, Sultana N, Siddiqui FA, Naseem S, Qureshi F. Simultaneous determination of pyrimethamine, sulfadoxine, mefloquine, and ibuprofen in pharmaceutical formulations by RP-HPLC. Med Chem Res. 2010;19:1043-1054.

41. Sultana N, Arayne MS, Naveed S. Simultaneous quantitation of captopril and NSAID's in API, dosage formulations and human serum by RP-HPLC. Journal of the Chinese Chemical Society. 2010;57:62-67.

42. Sun Y, Takaba K, Kido H, Nakashima MN, Nakashima K. Simultaneous determination of arylpropionic acidic non-steroidal anti-inflammatory drugs in pharmaceutical formulations and human plasma by HPLC with UV detection. J Pharm Biomed Anal. 2003;30(5):1611-1619.

43. Siddiqui FA, Mirza AZ, Zuberi MH, Qureshi F. Optimization of quantitative analysis of buclizine hydrochloride using UV spectrophotometry in bulk drug and dosage formulations. Med Chem Res. 2011;20(1):121-124.

44. International Conference on Harmonisation of Technical Requirements for Registration of Pharmaceuticals for Human Use. Validation of Analytical Procedures Text and Methodology: Q2(R1). ICH Harmonised Tripartite Guideline. IFPMA: Geneva; 2005. Available from: http://private.ich.org/LOB/media/MEDIA417.pdf. Accessed September 9, 2012.

45. Lister AS. 7 validation of HPLC methods in pharmaceutical analysis Sep Sci Technol. 2005;6:191-217.

46. Center for Drug Evaluation and Research (CDER). Reviewer Guidance: Validation of Chromatographic Methods. Center for Drug Evaluation and Research (CDER), US Food and Drug Administration: Silver Spring, MD; 1994. Available from: http:/www.fda.gov/downloads/ Drugs/.../Guidances/UCM134409.pdf. Accessed September 9, 2012.

47. United States Pharmacopeial Convention. Validation of Compendial Methods. United States Pharmacopeia - National Formulary. Section $<1225>$. Rockville, MD: United States Pharmacopeial Convention; 2007:549.

48. Dong MW. Modern HPLC for Practicing Scientists. Hoboken, NJ: John Wiley \& Sons; 2006.

49. Plackett RL, Burman JP. The design of optimum multifactorial experiments. Biometrika. 1946;33(4):305-325.

Research and Reports in Medicinal Chemistry

\section{Publish your work in this journal}

Research and Reports in Medicinal Chemistry is an international, peerreviewed, open access journal publishing original research, reports, reviews and commentaries on all areas of medicinal chemistry. The manuscript management system is completely online and includes a very quick and fair peer-review system, which is all easy to use.

\section{Dovepress}

Visit http://www.dovepress.com/testimonials.php to read real quotes 